\title{
The Elderly Health Office-Public Health Respond to the Ageing Challenge
}

\author{
Irena Dzeletovic Milosevic, Dusanka Matijevic and Svetlana Mladenovic Jankovic \\ Public Health Institute of City of Belgrade, Belgrade 11000, Serbia
}

\begin{abstract}
Introduction: Demographic structure in Belgrade is regressive biological type with $16.4 \%$ of the Elderly in whole population. Addressing this fact Public Health Institute of City of Belgrade in 2008 established the EHO (Elderly Health Office). Aim: This paper emphasizes the importance of Public Health response to ageing population challenges. Method: This public health study is retrospective review based on work of EHO from 2008 to 2017 year. Results: Numerous health promotion activities were performed by EHO: development guidelines for elderly care services coordination as well as for effective communication within health care system; development of age-friendly web portal; cooperation with the mass media; building partnership with representatives of the state- and private-owned facilities and NGOs (non-governmental organizations); support to strengthening inter-generation cooperation; promotion of elderly age-friendly phone line; organizing and participation in public health events, meetings and conferences. EHO participated in evaluation capacities of healthcare in Belgrade, regarding human resources, equipment and facilities, and monitoring elderly health status. Conclusions: The role of the EHO of IPHB is: (1) support to active, healthy, productive ageing of the citizens of Belgrade; (2) strategic planning of the Elderly health care; (3) strengthening of intersectional cooperation. Measures suggested: Public Health approach of EHO is response to challenges of ageing population and potential model for age oriented program management.
\end{abstract}

Key words: The elderly, public health, health promotion.

\section{Introduction}

The Office for the Elderly and Socially Deprived Groups was established in 2008 within the Public Health Institute of the City of Belgrade upon the initiative of the Government of the Republic of Serbia and in accordance with the age structure of the population in Belgrade, specific needs of elderly people, especially these over 65 and applicable legislation. Since the very beginning the Office for the Elderly and Socially Deprived Groups has prioritized the focus on difficulties and needs of elderly population with the aim to improve conditions for active, healthy, productive ageing of the Belgrade population, supported by the health policy. Therefore, in 2014, regarding the spotlight of interest and activities in the previous period the Office for the Elderly and Socially Deprived Groups was renamed into the EHO (Elderly

Corresponding author: Irena Dzeletovic Milosevic, DDs, public health specialist, research fields: the elderly public health and the elderly health promotion.
Health Office), and prepared a set of plans and strategic documents important for the health of elderly population.

Scientific forecast of the UN for the following decades points out the necessity to direct all segments of the society towards the improvement of the protection of this cluster of the population, in accordance with the positive experience of the developed countries [1].

The existing system of health and social care in Serbia recognizes the specificities of the needs of elderly people, but the possibility for the appropriate response has not been always equivalent. Coordination of mutual activities, partnership between government and non-government sectors in supporting healthy ageing of this explicitly vulnerable cluster of population are also specific issues to be dealt with [2].

The Office, among other activities, also has got mediating and coordinating role in connecting different sectors, the role of the guide through different systems 
in which the elderly people have difficulties in managing their way, in order to respond to the needs of the elderly as quickly as possible, adequately and always with the broadest possible support: emotional, psycho-social, economic, etc.

Regarding this, EHO succeeded in realizing numerous activities since it was established in 2008, especially intensified in period between 2014 and 2017.

\section{Aim}

This paper emphasizes the importance of Public Health response to ageing population challenges.

\section{Materials and Method}

This public health study is retrospective review based on work of EHO and routine statistical data from 2008 to 2017 year in Belgrade. The review is focused on activities and approaches implemented by EHO as well on figures about the Elderly health status. A descriptive analytical method was used.

\section{Results and Discussion}

\subsection{Age Structure and Health Condition of Elderly People}

The age structure in the city of Belgrade, as well as in the whole Serbia, matches explicitly regressive bio-type, regarding the fact that the number of elderly people in total population of Belgrade, according to the census of 2011, was $16.4 \%$. There are over 1.7 million retired people in the whole Serbia [3, 4].

The analysis of health status shows that out of 271,762 citizens of Belgrade over 65 years every fourth person $(68,170)$ was subject to the hospital treatment in 2015 [5]. The rate of hospitalization increased in the last ten years from 202 to 251/1,000. The most common reasons for hospital treatment are bloodstream system diseases: apoplexy, acute myocardial infarction, chest pain (contractions), as well as fracture of the femur and cataract. The number of the hospitalized due to the tumor has been almost doubled for the last ten years. There is also a significant increase of the treated for the diseases of the musculoskeletal system and respiratory system diseases, while the number of patients on hospital treatment for eye diseases has been halved. The male patients are more often users of hospital care (the rate of hospitalization is $296 / 1,000$ ) than female patients $(219 / 1,000)$.

In 2015 there were 4,094 citizens of Belgrade over 65 and older treated in hospitals due to the injuries, and the rate of hospitalization was 15.1/1,000 with a trend of growth. In this age cluster, the rate of hospitalization due to injuries was higher in female patients (17.1/1,000, while at male patients it was $12.1 / 1000)$, and the dominating injury was the fracture of the femur.

Totally, 6,158 citizens of Belgrade over 65 and elder suffered of malignant diseases. The morbidity rate of malignant neoplasm is $2.266 / 100,000$ citizens and it is 4 to 5 times higher than the rate in the age of the adults from 20 to 64 . The elderly are most affected by carcinoma of digestive system, skin, respiratory organs, breast and carcinoma of the urinary system. A total of 3,607 citizens of Belgrade over 65 and elder died of malignant diseases in 2015, out of which 1,065 were due to malignant tumor of digestive organs and 800 due to the respiratory system malignant tumors.

Totally, 16,676 citizens of Belgrade over 65 died in 2015 (79\% of all the deaths). The morbidity rate was $68.7 / 1,000$ and for the last ten years it has shown a declining trend. The morbidity rate in male population $(82.2 / 1,000)$ was higher than in the female population (59.2/1,000). Lethal outcomes are most often caused by diseases of the circulatory system and tumors.

The elderly population differs in many ways except in the old age. These differences are reflected in the health, socio-cultural and socio-economic characteristics, lifestyles, interests. A special problem is poverty in the old age.

Differences in the health condition of the elderly require relevant and very specific interventions. 
Health profile of the elderly people [6]:

- Healthy elderly people

- Elderly people with pronounced factors of risk to health (unhealthy lifestyles, obesity, levels of involvement in social flows)...

- Elderly people in need of immediate care and protection

- Elderly people with chronic diseases/conditions

- Elderly people with multiple and complex chronic conditions (for example, associated physical inability with mental dementia)

Therefore, equality in the health of the elderly is of crucial importance for public health both as for health and social policy in Belgrade and in Serbia in general.

4.1.1 The Current Situation in the Field of the Healthcare of the Elderly

In accordance with their role in strategic planning, EHO has conducted the analysis of available resources, needs and suggestions for possible solutions in regard to the increased requirements for health care.

The capacity of healthcare institutions in Belgrade, regarding human resources, equipment and facilities, that are exclusively intended for healthcare of the elderly, has been reviewed in the field of primary and secondary healthcare.

\subsubsection{Primary Health Care}

Within the field of primary health care there were evaluated capacities in health care institutions which provide primary health care services [7].

Health care to elderly people in these institutions (Primary Health Centers) has been provided in the existing organization units which offer services to the adult population through the chosen general practitioner. Service departments in the Primary Health Center which provide health care for the elderly and socially deprived groups include different activities in the fields of home treatment, polyvalent nurses, activity of social workers and psychologists. Their services are provided by teams, in cooperation with the chosen general practitioner. Services for the elderly are provided in Preventive centers. There was a remark that these team activities have not been equally developed in all of 17 Primary Health centers in Belgrade. Due to the increasing trend in needs for elderly population healthcare, the specified services still do not have sufficient professionals, necessary equipment and there is a need for special vehicles for external calls. It is obligatory to make visit to one elderly person at least once a year by a professional from the patronage service (community nurses and medical technicians), if such person has been registered in referent record book for such need. In some special cases there is established cooperation with the Municipality social care center, Red Cross and other NFOs (non-government organizations) within the municipality.

The facilities of the Primary Health Centers have not been sufficiently adapted for the admission of the elderly and less mobile persons, especially these in wheel chairs. Also, there is a particular issue of the existence of adequate toilets for people with disabilities in PHC. There are no specially separated facilities, equipment and staff intended for healthcare of the elderly population in the City of Belgrade.

\subsubsection{Other Healthcare Institutions of the Primary} Level

The healthcare institution specified for providing primary healthcare services for the functionally disabled elderly people is the City Institute for Gerontology and Palliative Care, which has available facilities, equipment and staff to conduct healthcare services to the people over 65 in the inner city area of Belgrade. This Institute has 20 vehicles for providing healthcare services to the external functionally disabled users.

\subsubsection{Secondary Healthcare}

As for the health care institutions which provide secondary health care there are no separated facilities, equipment and staff intended for the elderly people [8].

An example of recognizing the specificities of healthcare for the elderly has been realized in the area of mental health, that is, in the Institute for Mental 
Health in Belgrade, in the Department for specialist consultative examinations on the Clinics for adults, by establishing the Cabinet of the Third Age, as a specialized unit for the Elderly. The Cabinet was given appropriate facilities for the outpatient medical examinations and interventions, working cabinet and room for staff, working and team meetings. In the equipped space, the staff provides all services of healthcare (primary, secondary and tertiary) as well as social care services.

In two out of the existing four Clinical Hospital Centers in Belgrade, there have been working specially intended capacities for the elderly people, for several decades, including in total 137 hospital beds and 3 outpatient beds, although elderly patients make $48 \%$ at the Clinic for Internal Medicine, while at the Surgery Clinic the elderly people make $36 \%$ of hospitalized patients.

Other hospital health facilities, for hospital treatment of the elderly population, which make up a large part of hospital patients, see the solution only in the expansion of space, a greater number of employees and defined special equipment.

\subsection{The Elderly Health Office}

\subsubsection{Objective}

The objective of EHO is active, healthy and productive ageing of the citizens of Belgrade, which can be achieved only by the combined action of all stakeholders (partner participation) and those responsible in particular from the health and social care sector, with positive health, social and state policies as a whole [9].

\subsubsection{Particular Objectives of EHO}

(1) Improvement of the health of the elderly

(2) Better functioning of the current system of the health care intended to the elderly

(3) Improvement of the activities coordination among all segments and levels of healthcare services intended to the elderly population

(4) Mediation and coordination of the activities of different institutions in government and non-government sectors in a common function-response to the needs of the elderly population

(5) Constituting of multi-sector and multi-discipline model of promotion of the healthcare of the elderly, which can be sustainable also in other regions of Serbia.

\subsubsection{Mission and Vision of the Office}

(1) Mission

Comprehensive care, especially healthcare is available for all senior citizens in accordance with their specific needs.

(2) Vision

The Office is a holder of public health activities in function of active and healthy ageing of the citizens of Belgrade and positive model for Serbia.

By strengthening its Public-Health role, EHO should raise the awareness of medical and social workers, as well as all citizens, to be actively involved in prevention of chronic non-infectious diseases which particularly affect this population cluster. The affirmation of the recommendations for healthy life styles and increased respond for preventive medical checkups and screening of the risk for developing chronic non-infectious diseases are of great importance in this area.

Equality in health and more efficient response to the needs of the elderly means [10]:

- supporting elderly people, including the population with specific needs, to take best care of their health

- strengthening the restorative focus of health services to better meet needs of elderly people

- establishing coordinated specialists' services to ensure high quality health care for elderly people with complex needs

- strengthening partnerships with selected general practitioner/medical doctor

- community care sector

- supporting informal care/care-givers 
Planning of the comprehensive care, particularly healthcare for the elderly population is not a novel and is grounded in certain tradition in Serbia.

Strategic planning of healthcare for elderly population is particularly important because it has widely conceived contents and regarding this, there has been conducted analysis of the current structures in the community, surroundings, needs and proposition for possible solutions in regard to the specific needs for healthcare of the elderly population. Long-term objectives in this field and establishing appropriate measure are practically the outcome of these analyses, which are to define the factor and prerequisites important for the development of healthcare of the elderly population both in present and in the future.

Coordination and mediation role of EHO in regard to the activities of different institutions of government and non-government sectors dedicated to the elderly is specific and unique.

Numerous activities of EHO are exactly realized through the activities and interventions in this field, primarily in the local community, which represents very concrete contribution to the general overview of the importance of these coordinating and mediating functions significant for positive outcomes when we come to the responding to different and often complex needs and issues of the elderly.

Specificities of the work of EHO reflect also through its focus, before all, to prevention and improvement of the health of the elderly, as well as providing support in resolving their actual needs and issues. Active healthy ageing is the top objective of EHO activities as well as all forms of support to this population cluster.

\subsection{Activities of the Elderly Health Office}

Since establishing EHO has been conducting numerous activities, the following text shows some of the most important ones.

(1) The team of EHO has created and made four editions of the age-friendly publications "The Guide for Coordination of the Care Services of the Elderly
Population in Belgrade and Informing of the Professional Public on Basic Principles of Integrated Care of the Elderly Population”. The Guide includes locations and phone list of the relevant city services: home care service, Polyvalent nursing services, network of geriatric hospital facilities, all centers for social affairs, all home care services, all day care centers and clubs for the elderly in municipalities in the city of Belgrade.

(2) Beside these data they provide as well actual, relevant recommendations for healthy, active and productive ageing (publications 2009, 2013, 2015, 2017).

In order to improve communication between elderly healthcare users and healthcare service providers, there was created a publication "Better and Faster", the Guide for better and faster communication with the elderly for the employees in the healthcare services. It is distributed both to the elderly population and professionals and partners, including all interested citizens.

(3) The age-friendly internet page (www.zdravljestarih.org.rs) was created in 2014 with intention to provide for the increasing population of the elderly Internet users as well as for all others interested in, all necessary information on different topics in the healthcare area, important contacts from the healthcare services and social care services, age-user friendly. www.zdravljestarih.org.rs is providing contemporary information in the field of health, proper nutrition, socializing and cultural events in their surroundings. This website also may provide the tracking of their laboratory analysis in the City Institute for Public Health. Also it is offered information about the current quality of water, air, soil, noise level in the environment where the elderly live. This website also reminds the elderly for seasonal vaccination and advantages of vaccination in the third age. There it is possible to find the current conditions of the activity of allergens in the air, how to protect themselves and prevent possible health complications. During the 
festive time/holidays all users may read about paying attention to the modest consuming of food and drink.

Our articles break the mischief about Anesthetics, Sexual life etc. in the third age.

The topics are harmonized also with the suggestions of our users who can always write about their interests and ideas to the email address: kancelarijazastare@zdravlje.org.rs.

The increasing number of elderly users of the Internet and social networks has been noticed in reviewed period 2014-2017.

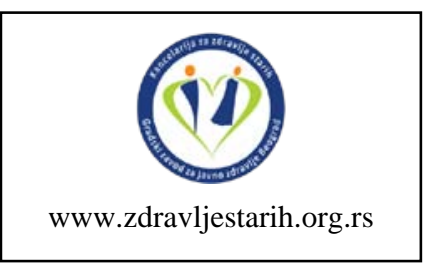

(4) New publications are being created and distributed for each new season: "Tips for Healthy Ageing: Winter, Spring, Summer and Autumn”.

(5) We regularly participate in the mass media: press, magazines, professional publications, electronic media on the elderly population health promotion:

- "Third Age" on National Serbian Television RTS1,

- Special show on RTS2: "All Colors of Life" family TV magazine,

- Radio broadcasting: "Reaching a Century" of the Radio Belgrade Broadcast No. 1,

- Regular column in the monthly magazine Retirement, etc.

(6) Realization of numerous partnerships with the state and private institutions and NGO sector which support humane relations and inter-generation cooperation with the elderly and towards the elderly (cooperation with the Senior Clubs, monthly magazine Retirement in the form of the regular column devoted to the health of the elderly in the widest possible sense, the Red Cross concerning education and gaining skills important, before all, for the health of the elderly but also for their other needs, such as using different services in the local community which may improve the elderly life quality, and similarly, including the care givers for the elderly).

(7) Establishing and maintaining of the inter-generation cooperation of the students and teachers from the Eight's Belgrade High School with the elder generations with the aim to improve health of all generations in the partners' relation (care and help to the elderly in the surroundings who are not able to perform some daily activities and tasks: going shopping, reading books, magazines, daily press, going together to the theatre, going out for a walk, playing chess, dominos etc.). This is the way to keep the relation between elderly and younger generations, by while the younger improve their responsibility.

(8) In order to support all these oriented toward the needs of the elderly, the charter named "Elderly Health Friendly" was created in 2015. The Charter is awarded to the institutions, associations, companies, individuals that, with their efforts and positive approach-especially support, help and in any other way meet the needs of the elderly population, improving, before all, their life quality. Up to now there have been 40 charters awarded with the intention to increase that number.

(9) After recognizing the needs of the elderly, EHO in cooperation with the City Institute for Emergency Medical Services, Belgrade, introduced in 2011 the special phone line: "You've Got a Friend" which is intended to all who are not in life risk, but have the need for health or social care, and have no one or do not know to whom to address. After receiving the call, a trained professional advises and makes the elderly about the appropriate contact. In such manner it is possible to reduce discrimination of the elderly patients in the healthcare system, increasing its availability and accelerating appropriate and on-time response to their needs.

(10) The EHO Team has regularly participated in all “Third Age Fairs” which have been held in Belgrade at the Belgrade Fair since 2014, twice a year. It is the place in which it is possible to gather a large number of 
participants and visitors. In the partnership with the Gerontology Center Belgrade and Senior-media, organizers of this important manifestation, EHO achieves medical screenings and provides health and educational lectures and consulting of the visitors of the Third Age Fair.

There are a lot of different contents intended to the elderly at one place on these fairs, such as: different medical services by the state and private sectors, banking services for the elderly, offer of the spa-treatments and tourist arrangements created appropriately, products which make life easier in the third age, life insurance services, additional health insurance, special recreation programs for the elderly. On this occasion the elderly participants usually present their skills in painting, singing, folk dancing, poetry. Also, it is an opportunity for the contest of the Miss Senior Beauty, covered by media. The Fairs are under the auspices of the Republic of Serbia and the Ministry for Social Affairs and Policy as well as the Belgrade City Mayor.

The Office conducts specially designed questionnaire about the life style of the elderly, anthropometric evaluation and basic check up of other medical parameters (blood pressure, glucose test etc.) on these Third Age Fairs.

Also male and female pensioner with the best psycho-physical condition including their appearance is being chosen during this event. Special attention is given to the organization of medical educational lecturing and workshops with the special focus on health promotion and active ageing of the generations over 65.

(11) The Office in the capacity of the partner, has been successfully implementing projects in the area of healthcare education and medical checkups of the elderly in Belgrade in cooperation with the NGO-City organization of pensioners of Belgrade, the most massive organization of the pensioners in the Republic of Serbia, which include pensioners from all Belgrade municipalities organized in the associations.
They also organize socializing which are especially focused on healthy life styles and active ageing.

(12) Since it was established, EHO has been involved in organization of all ten "Olympiads of Sport, Health and Culture for the Third Age" managing the health sector. Early morning "Health Bazaars" turned out to be very popular and successful show. They consider check-ups of medical parameters such as: blood pressure, glucose and lipide tests, eye vision and eye pressure checkups and determining BMI as well as conducting a survey of lifestyles. Health education is organized in the topics in which the elderly are most interested. Over 10 years in a row, the "Olympiads" have been bringing together more than 11,000 full-time Serbian pensioners as well as guests from the USA, Russia and Sweden. The EU Ministerial Conference praised and rewarded the Olympiads in 2012 for being an example of good practice in Europe.

(13) There is quite intensive and continuous cooperation with the local community through organizing interactive meeting such as You Can Do This (where it is pointed out that all elderly, as well as the young ones may equally participate in life, improvement of their health, only if they want that and are willing to do that. We invite not only these who already actively participants, but also these who are more passive and should be involved in the community. At these meetings which are organized in cooperation with the local communities there are appropriate health educational lectures, and beside that they also organize Senior Tango which introduces the wish for socializing among the elderly, by teaching/learning dancing steps which leads to better health on two levels: through the school of dancing for the beginners and dancing parties for these more skillful in dancing.

(14) Each year EHO participates in organizing appropriate events on the occasion of the 1st October "International Day of the Elderly" throughout the series of activities, one of the already traditional manifestations is certainly "Dance to a Healthy Heart in Youth to Old Age”. 
(15) EHO successfully represents the results of their activities on the relevant congresses and conferences in the country and abroad as well as in domestic and international professional publications.

(16) Representatives of EHO are participants and moderators of the International Congress of Gerontology of Serbia, the most important experts gathering in the field of Gerontology and Geriatrics in Serbia.

Public Health recommendations in order to meet growing needs of Elderly are: tailor health systems to provide older-person-centred and integrated care; prevent chronic conditions; develop long-term care; better use of existing resources and adoption of new technologies; create age-friendly environments and remove barriers to participation, promote capacity-enhancing behaviors; reduce inequities and enable choices for target population.

\section{Conclusions}

(1) The EHO aims to support actively, healthy, productive aging of inhabitants of Belgrade. It provides Public Health respond to needs of aging population and model for age oriented management. The mediating and coordination of different sectors has role of guidance through a diverse range of services dedicated to the Elderly wellbeing, and with the broad public support.

(2) The EHO continuously works on improving communication among elderly and health care providers. The establishment of a special telephone line for needs of the elderly in cooperation with City Institute for Emergency Medical Services, Belgrade, contributes for better communication. This phone line is intended for elderly without needs for emergency medical assistance but still in health, social and other type of care needs. Specially trained health professionals and associates provide relevant information and respond to their concerns.

(3) The Age-friendly website which EHO team regularly updates, contains useful and up-to-date information and advices important for older Internet users.

(4) The Elderly Health Office successfully implemented projects in the field of Elderly health education and health care in Belgrade in cooperation with governmental and nongovernmental organizations. EHO organizes joint gatherings that focus on healthy lifestyles and active, productive aging and support intergeneration cooperation between students and teachers of High Schools and older citizens. This contributes to the development of awareness of intergenerational solidarity, respect and care according to needs of elderly. Public Health approach of The Elderly Health Office is response to challenges of ageing population and potential model for age oriented program management.

\section{References}

[1] https://ourworldindate.org. The Size of Population UN Population Projection by Country and World Region until 2100, University of Oxford, 2017.

[2] Belgrade Public Health Institute. 2016. The Analysis of the Medical Conditions of the Citizens of Belgrade in 2015; Public Health Institute, Belgrade.

[3] Belgrade Public Health Institute. 2016. Statistic overview of medical activities in Belgrade for 2015; Public Health Institute, Belgrade.

[4] Institute for Public Health of Serbia. 2016. Health Statistics Yearbook of the Republic of Serbia; Public Health Institute, Belgrade.

[5] Belgrade Public Health Institute. 2016. Analysis of Medical Condition of Belgrade Citizens in 2015; Public Health Institute, Belgrade.

[6] MacAdam, M. 2008. "Frameworks of Integrated Care for Elderly: A Systematic Review.” Canadian Policy Research Network Report, Ontario.

[7] Belgrade Public Health Institute. 2016. Analysis of the Work of Outpatient Health Institutions and the Use of Primary Health Care in Belgrade in 2015, City Public Health Institute, Belgrade.

[8] Belgrade Public Health Institute. 2016. Analysis of the Work of Stationary Healthcare Institutions and the Use of Hospital Healthcare in Belgrade in 2015; City Public Health Institute, Belgrade.

[9] Tomek-Roksandic, S. 2005. “The Importance of Centers for Gerontology of County Institutes of Public Health and Gerontology centers in Croatia.” Medicus 14 (2): 177-92. 
[10] Health Service Framework for Older People 2009-2016: Improving Health \& Wellbeing Together/South Australia,
Dept. of Health. State Wide Service Strategy Division, available at: http://www.sahealth.sa.gov.au/wps/wcm/. 